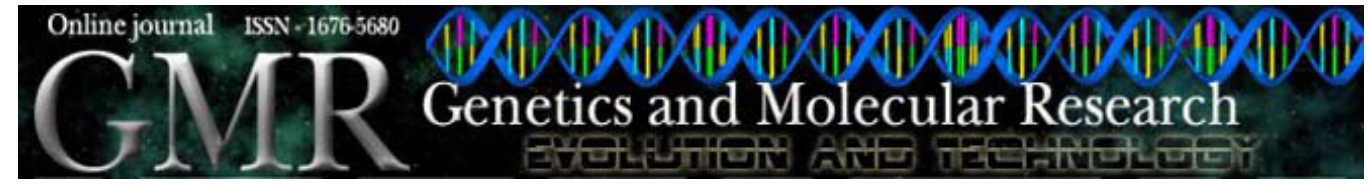

\title{
Distinction between plant samples according to allele dosage by semiquantitative polymerase chain reaction
}

\author{
F.A. Martins' ${ }^{1}$ P.C.S. Carneiro ${ }^{1}$, C.T. Guimarães ${ }^{2}$, J.V. Magalhães $^{2}$, \\ J.E.S. Carneiro ${ }^{3}$ and C.D. Cruz ${ }^{1}$ \\ ${ }^{1}$ Departamento de Biologia Geral, Universidade Federal de Viçosa, \\ Viçosa, MG, Brasil \\ ${ }^{2}$ Embrapa Milho e Sorgo, Sete Lagoas, MG, Brasil \\ ${ }^{3}$ Departamento de Fitotecnia, Universidade Federal de Viçosa, \\ Viçosa, MG, Brasil \\ Corresponding author: F.A. Martins \\ E-mail: franufv@hotmail.com
}

Genet. Mol. Res. 8 (1): 319-327 (2009)

Received January 15, 2009

Accepted January 26, 2009

Published March 17, 2009

\begin{abstract}
The lack of informativity of samples from heterozygotic individuals is one of the hindrances in the mapping of quantitative trait loci of outbred populations, since it is not normally possible to identify the origin of each allele. One way to include these individuals in analyses would be to genotype their endosperm, considering that a heterozygote ( $A a$ ) has $A A a$ or $A a a$ endosperm, when the female genitor donates the $A$ or $a$ allele, respectively. We used semiquantitative polymerase chain reaction to determine allele dosages in DNA mixtures, by simulating the observed conditions for endospermic tissue. Semiquantitative polymerase chain reaction on agarose gels, along with regression analysis, allowed differentiation of the samples according to the amount of DNA. This type of information will help decrease the number of non-informative individuals in quantitative trait locus mapping of outbred populations, thereby increasing mapping accuracy.
\end{abstract}

Key words: Allele dosage; Endosperm constitution; Maize; Semiquantitative polymerase chain reaction 


\section{INTRODUCTION}

The simplest detection procedure for quantitative trait loci (QTLs) is analysis based on a single locus, which consists of the statistical comparison among phenotypic mean values of character for the different evolved classes of genotypic markers. A significant result describes the existence of a linkage between a marker and a QTL of the related character (Coelho, 2000). The detection of a defined QTL depends on various parameters such as magnitude of effects over a certain characteristic, assessed population size, and recombination frequencies between marker and QTL, as well as the inheritance of such characteristic (Tanksley, 1993). In the mapping of outbred populations, it is not a certainty that the genotypes of the genitors are known (Slate, 2005), which means that is not possible to identify from the heterozygous offspring the origin of each of the alleles, the linkage phase between marker and QTL, and thus, it is impossible to estimate the recombination frequency among these loci (Da and Lewin, 1995).

The lack of informativity from heterozygotic individuals is one of the difficulties in the QTL mapping of outbred populations (Liu, 1998). For this reason, such individuals are omitted in the analyses of mean contrasts, and thus, they do not contribute to QTL detection. Taking into account that endosperm is formed by the fusion of a male gamete with the two polar nuclei of the female gametophyte, and that fusion generates, by mitotic divisions, triploid endosperm nuclei with two copies of the maternal alleles and one copy of the paternal allele in its genomic DNA (Wu et al., 2002), it is possible to conclude that a useful tool for including heterozygotes in the analyses would be genotyping their endosperm, since it is expected that a heterozygote $A a$ has endosperm $A A a$ or $A a a$, when its female genitors donate the allele $A$ or $a$, respectively.

Among the most recent methods for quantification of polymerase chain reaction (PCR) products, real time-PCR is especially noted. Although sensitive and reliable, this method is still expensive and requires special equipment, which not only limits its routine use in many laboratories but also points to the necessity of simplification and reduction of costs, by adapting such techniques. In this sense, semiquantitative PCR (SQPCR) has been successfully adapted. Underwood et al. (1994) were the first to propose the determination of the number of genes by comparing samples with a standard curve, plotted based on DNA amplification of samples with previously determined gene dosages. In the last years, semiquantification works have been carried out in a similar way in a wide range of cases such as in the investigation of human diseases (diagnosis and determination of cytomegalovirus load in the leukocytes of bone marrow or kidney transplant patients (Marin et al., 2004) and determination of interferon-gamma mRNA levels in AIDS-free HIV-infected individuals (Barabás et al., 2001)), the identification of mixtures containing conventional and genetically modified maize seeds (Tozzini et al., 2000), or the determination of transgenic maize and soybean composition in processed foods (Cazzola and Petrucelli, 2006). However, its longest and most frequent use is in the analysis of gene expression, that is SQPCR, for instance, in the study carried out by Chelly et al. (1990) concerning the expression analysis of the gene for muscular dystrophy, or in the distinction between queen and worker bees according to the production of mRNA for the enzyme methyltransferase (Baffi et al., 2004).

In many previous reports, the semiquantitative potential of PCR has been demonstrated by comparing it to classical means of nucleic acid semiquantification, such as Northern blot analysis or in situ hybridization. Dutta et al. (2007) reported that the results of PCR-based semiquantification of genes and expression regulators from the terpenoid 
indole alkaloid pathway, in Catharanthus roseus cell cultures, indicated a good correlation with results obtained by traditional Northern blot analysis. Semiquantitative PCR has also been shown to correlate with in situ hybridization. This was well exemplified by Tao et al. (2007) who studied the temporal expression and localization of the phytoene synthase gene during fruit ripening in Citrus sinensis. Their results demonstrated that an equivalent proportionality in the relative amount of RNA could be obtained by both PCR and in situ hybridization.

Although SQPCR does not permit an absolute quantification, the above-mentioned works demonstrated that it was possible to estimate the relative amount (Chelly et al., 1990; Baffi et al., 2004; Dutta et al., 2007; Tao et al., 2007) or the number of amplified molecules in each sample (Underwood et al., 1994; Tozzini et al., 2000; Marin et al., 2004; Cazzola and Petrucelli, 2006). The sensitivity of SQPCR is the result of a chain reaction, in which the products from one amplification cycle serve as substrates for the next, resulting in an exponential increase of the product. Theoretically, the amount of product doubles with each cycle of PCR, but in fact, beyond a certain number of cycles, the amplification efficiency decreases with increasing cycle number, resulting in a plateau (Gause and Adamovicz, 1994). It is essential to identify the exponential phase (or log-linear range) of the reaction, where the quantified amount of amplified target is proportional to the initial amount of target molecules, since the linear range could be defined as the assay's window in which quantification is possible (Ferre, 1992). Thus, in order to make use of SQPCR, it is necessary to know the reaction kinetics beforehand, to determine the ideal reaction time in which the PCR products correspond to the exponential phase, when the estimation can be more accurate (Chelly et al., 1990).

Owing to the potential use of SQPCR for the estimation of the number of amplified molecules, the aim of this study was to make use of this method for the distinction of samples, in relation to allele dosage in a DNA mixture that simulates the conditions observed in endosperm tissue of maize.

\section{MATERIAL AND METHODS}

\section{Plant material}

Maize leaves of the inbred lines L3 and L1113-01, provided by Embrapa Milho e Sorgo, were used. The molecular procedures were carried out at the Núcleo de Biologia Aplicada, in Sete Lagoas, Minas Gerais.

\section{DNA extraction}

DNA was extracted from the inbred lines according to the method described by SaghaiMaroof et al. (1984). DNA quantification was performed on a $0.8 \%$ agarose gel, using a DNA standard of known concentration. After electrophoresis at $100 \mathrm{~V}$ for $1 \mathrm{~h}$, the gel was treated with ethidium bromide $(1 \mathrm{mg} / \mathrm{mL})$ and visualized under ultraviolet light with the Eagle-Eye II (Stratagene). The DNA used in the following procedures was that of the individual inbred lines, and mixtures in the proportions of 1:2 (10 ng L3 DNA and $20 \mathrm{ng}$ L1113-01 DNA) and 2:1 (20 ng L3 DNA and 10 ng L1113-01 DNA). 


\section{Kinetics of the amplification reaction}

Initially, three pairs of microsatellite primers (simple sequence repeats), bnlg182, bnlg1006, and umc1653, polymorphic among the inbred lines, were selected based on the study of informativity and amplification pattern conducted by Padilha L (unpublished results) (Table 1).

Table 1. Primers and polymorphisms between the inbred lines L3 and L1113-01.
\begin{tabular}{lccc}
\hline Primer & Allele L1113-01 (bp) & Allele L3 (bp) & Polymorphism (bp) $^{\text {a }}$ \\
\hline bnlg182 & 400 & 112 & 288 \\
bnlg1006 & 224 & 171 & 53 \\
umc1653 & 93 & 112 & 19 \\
\hline
\end{tabular}

${ }^{a}$ Difference in size (in bp) between the amplified alleles. The values in bp indicate the size of the allele present in each of the inbred lines.

The amplification reactions were performed in a final volume of $10 \mu \mathrm{L}$ containing 30 ng DNA, $1 \mathrm{mM}$ Tris-HCl, $50 \mathrm{mM} \mathrm{KCl}, 2 \mathrm{mM} \mathrm{MgCl}, 125 \mu \mathrm{M}$ of each dNTP, $0.6 \mu \mathrm{M}$ of each primer and $1 \mathrm{U}$ of the enzyme Taq polymerase. The cycles in PCR consisted of an initial denaturation at $95^{\circ} \mathrm{C}$ for $2 \mathrm{~min}$, nine cycles at $94^{\circ} \mathrm{C}$ for $20 \mathrm{~s}, 68^{\circ} \mathrm{C}$ for $20 \mathrm{~s}$ with a decrease of $1^{\circ} \mathrm{C}$ per cycle, and $72^{\circ} \mathrm{C}$ for $20 \mathrm{~s}$, followed by $15-25$ amplification cycles at $94^{\circ} \mathrm{C}$ for $20 \mathrm{~s}, 60^{\circ} \mathrm{C}$ for $20 \mathrm{~s}$ and $72^{\circ} \mathrm{C}$ for $20 \mathrm{~s}$, in the study of amplification kinetics.

The amplified fragments were visualized on 3\% agarose gels after electrophoresis at $80 \mathrm{~V}$, for $2 \mathrm{~h}$. The gels were treated with ethidium bromide $(1 \mathrm{mg} / \mathrm{mL})$ and the image was captured with the Eagle-Eye II, under ultraviolet light. The images were analyzed with the ImageQuaNT ${ }^{\circledR}$ program (Molecular Dynamics) for quantification of band intensity.

\section{Estimation of copy number}

After determining the ideal number of cycles and the different DNA proportions of the inbred lines L3 and L1113-01 in the mixtures, new amplifications were performed for the primers bnlg182 and bnlg1006, in an attempt to propose models for different simple sequence repeat primers. Three repetitions were carried out for each primer, and the total number of amplification cycles was fixed at 30 , with the other reaction conditions remaining unchanged.

The intensity values observed in the three repetitions for the primers bnlg182 and bnlg1006 were converted into a scale from 0 to 100, in which the band intensities referring to the samples that contained DNA from only one of the inbred lines were considered to be 100 , and the other values were obtained by a simple rule of three. The converted data were subjected to variance analysis in order to test their conformity to the linear model.

Analysis of variance (ANOVA) and estimation of the regression parameters were performed with assistance of the GENES program (Cruz, 2006). Furthermore, the coefficients of determination (ratio between the sum of the squares of the regression and the treatment) were established, as well as the $95 \%$ confidence intervals for each independent variant in the different reactions. 


\section{RESULTS AND DISCUSSION}

\section{Kinetics of the amplification reaction}

Fragments amplified by the primer bnlg182 were observed after 28 cycles (Figure 1). Bands corresponding to the fragments of smaller size appeared more diffuse compared to the bands of larger fragments. Similar results were observed for the other primers, bnlg1006 and umc1653.

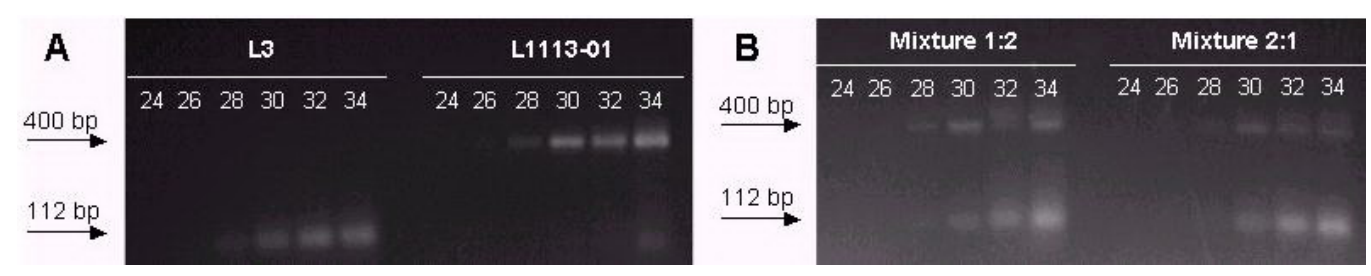

Figure 1. Electrophoresis of the samples of leaf DNA and the respective mixtures, on a $3 \%$ agarose gel, treated with ethidium bromide, showing the products amplified with the primer bnlg182. A. Reaction products with samples of DNA of the inbred lines L3 and L1113-01. B. Reaction products with the mixtures $(1: 2)$ and $(2: 1)$. The number of amplification cycles varied from 24 to 34 , with intervals of two cycles.

The intensity of the bands amplified by the primer bnlg182 was obtained with the ImageQuaNT ${ }^{\circledR}$ program, and the values corresponding to each reading were plotted (Figure 2). The kinetics study of the amplification reaction evidenced that, when individually amplified, the allele of smaller size reaches the plateau phase after 32 amplification cycles, whereas the allele of larger size reaches this phase after only 30 complete cycles (Figure 2A and B). When co-amplified, as in the mixtures, a greater difference was observed in the number of cycles needed to reach the plateau phase, since it was not possible to visualize it for the smaller fragment, while for the larger fragment a slight decrease in amplification was evident after 30 cycles (Figure 2C and D). According to Gause and Adamovicz (1994), the number of PCR cycles at which the plateau effect occurs varies greatly with the particular DNA sequence being amplified. The length of the fragment to be amplified is important, as is the initial total amount and concentration of DNA. As a result, the number of cycles at which the plateau effect occurs must be individually determined for each target sequence.

For the primer bnlg1006, with smaller polymorphism (Table 1), greater similarity was observed in the reaction kinetics (data not shown) for both alleles; however, for the primer umc 1653, the resolution of the 3\% agarose gel was not sufficient to clearly distinguish the amplified products, so that the analyses with this primer were hampered. This way, in studies of SQPCR that are intended to differentiate the allele dosages, the use of primers with alleles that do not display great polymorphisms and that show adequate size for discrimination on an agarose gel should be favored.

Also in Figure 2, it was observed that 30 amplification cycles was the number that best represented the exponential phase, seeing that in this phase the amount of amplified molecules is a function of their initial quantity (Chelly et al., 1990). Similar results were also observed for the primer bnlg1006. Thus, in the subsequent analyses, the number of amplification cycles was standardized to 30 . 
A
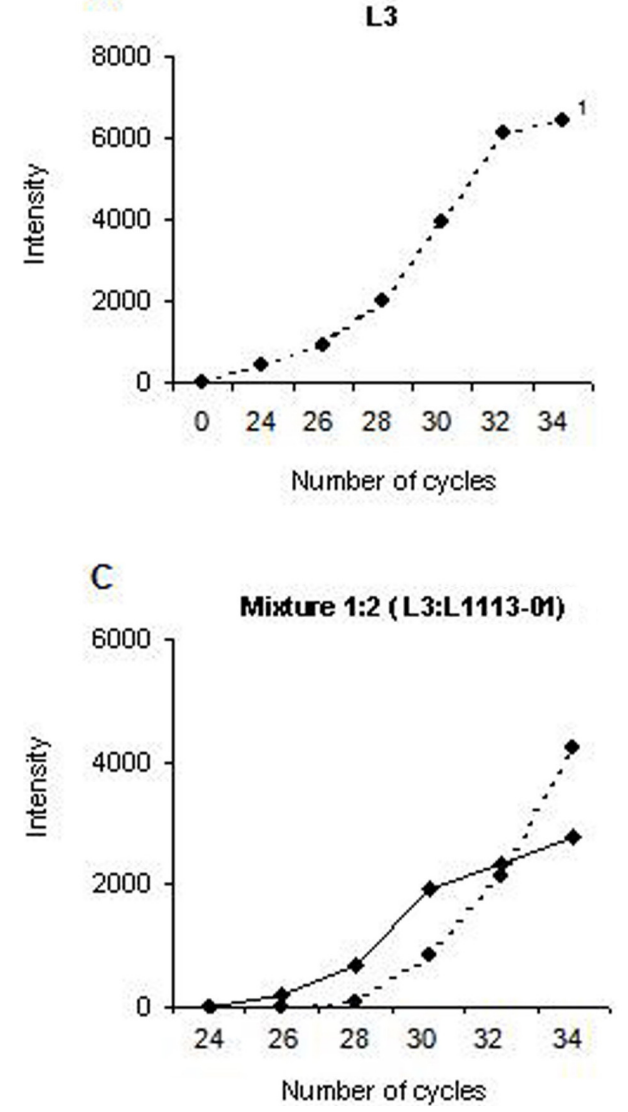
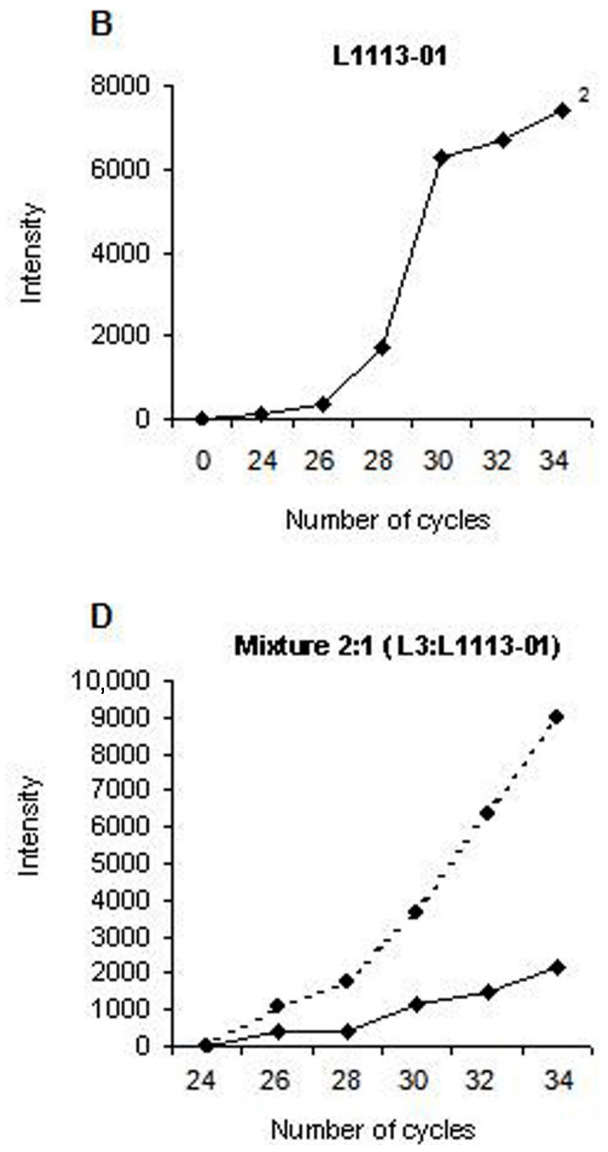

Figure 2. Reaction kinetics of amplification with the primer $b n \lg 182$. A. and B. Products of amplification reaction of the inbred lines L3 and L1113-01, respectively. C. and D. Products of amplification reaction of the mixtures 1:2 (10 ng L3 DNA and 20 ng L1113-01 DNA) and 2:1 (20 ng L3 DNA and 10 ng L1113-01 DNA), respectively. 1 and 2, kinetics of the amplification reaction of the alleles of smaller (L3) and larger (L1113-01) size, respectively.

\section{Estimation of copy number}

The analysis regarding the fragments with 30 amplification cycles permitted differentiation of the DNA amount of the inbred lines in all four samples (Figure 3). The intensity of the bands amplified by the primers bnlg182 and bnlg1006 was obtained with the ImageQuaNT ${ }^{\circledR}$ program, and the values corresponding to each reading were converted and subjected to analysis of variance (Table 2). The effect of the treatment was decomposed in regression effect and regression deviation. The latter appeared as not significant at $1 \%$ probability with the F-test, indicating a linear response of the band intensity with DNA amount, with coefficients of determination varying from 92.6 to $99.8 \%$. 

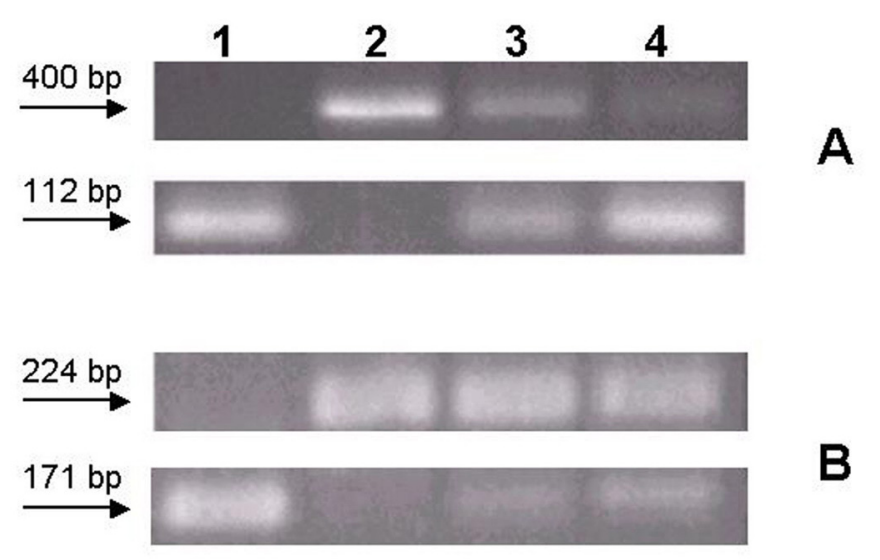

Figure 3. Electrophoresis of the amplification reactions with 30 complete cycles for the primers bnlg182 (A) and bnlg1006 (B) on a 3\% agarose gel. Lanes 1 and $2=$ samples with $30 \mathrm{ng}$ DNA from the inbred lines L3 and L111301, respectively. Lanes 3 and $4=$ samples with mixtures of DNA from the inbred lines L3 and L1113-01, in the proportions of $1: 2$ and $2: 1$, respectively.

Table 2. Summary of the variance analysis of the intensity values for the bands amplified by the primers $b n \lg 182$ and $b n \lg 1006$.

\begin{tabular}{|c|c|c|c|c|c|}
\hline \multirow[t]{2}{*}{ Source of variation } & \multirow[t]{2}{*}{ d.f. } & \multicolumn{2}{|c|}{$b n \lg 128^{\mathrm{a}}$} & \multicolumn{2}{|c|}{ bnlg1006 } \\
\hline & & $400 b^{b}$ & $112 \mathrm{bp}$ & $224 \mathrm{bp}$ & $171 \mathrm{bp}$ \\
\hline Treatment & 2 & $803.15^{\mathrm{c}}$ & 66.402 & 103.60 & 693.65 \\
\hline Regression & 1 & 1604.30 & 132.27 & 206.81 & 1285.19 \\
\hline Regression deviation & 1 & $1.99^{\mathrm{NS}}$ & $0.53^{\mathrm{NS}}$ & $0.38^{\mathrm{NS}}$ & $102.10^{\mathrm{NS}}$ \\
\hline Residual & 6 & 1.23 & 6.68 & 0.42 & 8.29 \\
\hline Coefficient of determination $\left(\mathrm{R}^{2}\right)$ & & $99.87 \%$ & $99.60 \%$ & $99.81 \%$ & $92.64 \%$ \\
\hline$\beta_{0}$ & & 50.50 & 86.1 & 82.2 & 53.7 \\
\hline$\beta_{1}$ & & 1.635 & 0.469 & 0.587 & 1.464 \\
\hline
\end{tabular}

d.f. $=$ degrees of freedom. ${ }^{\text {NS}}$ Not significant at $1 \%$ probability with the F-test. ${ }^{\text {a }}$ primer, ${ }^{b}$ length of the analyzed allele in bp, ${ }^{c}$ mean square value; $\beta_{0}$ and $\beta_{1}$ are the parameters estimated for the regression model.

Based on the estimation of regression parameters, graphs were obtained and the $95 \%$ confidence intervals were established for each independent variant in the different reactions (Figure 4). In the graphs representing reactions with the primer bnlg182 (Figure 4A), overlapping of confidence intervals for the larger allele (400 bp) was not observed. However, among nine intensity values that constituted the regression analysis, three did not belong to any of the intervals. Contrarily, for the smaller allele (112 bp), overlapping of confidence intervals was observed for the independent variant with amounts of 10 and $20 \mathrm{ng}$, as well as for 20 and $30 \mathrm{ng}$. Two of the analyzed intensity values were observed within the overlapping intervals; as a consequence, the initial DNA amount to which they correspond could not be estimated, since these intensity values may refer to the amplification of either one or the other initial DNA amount. The graph in Figure 4B, relating to the primer bnlg1006, did not show overlapping in the confidence intervals. However, regression analysis for the intensity values of the 
bands corresponding to the larger and smaller alleles did not explain all the observed values. For both alleles, three of the observations did not belong in any of the established intervals. Semiquantification by PCR, based on comparison between the intensities that correspond to the amplified products and a standard curve, plotted upon DNA amplification of samples with previously determined gene or allele dosages, was proposed for the first time by Underwood et al. (1994). These authors also observed overlapping of the confidence intervals, and reported that the initial gene quantity in the samples could not be determined in these intervals.
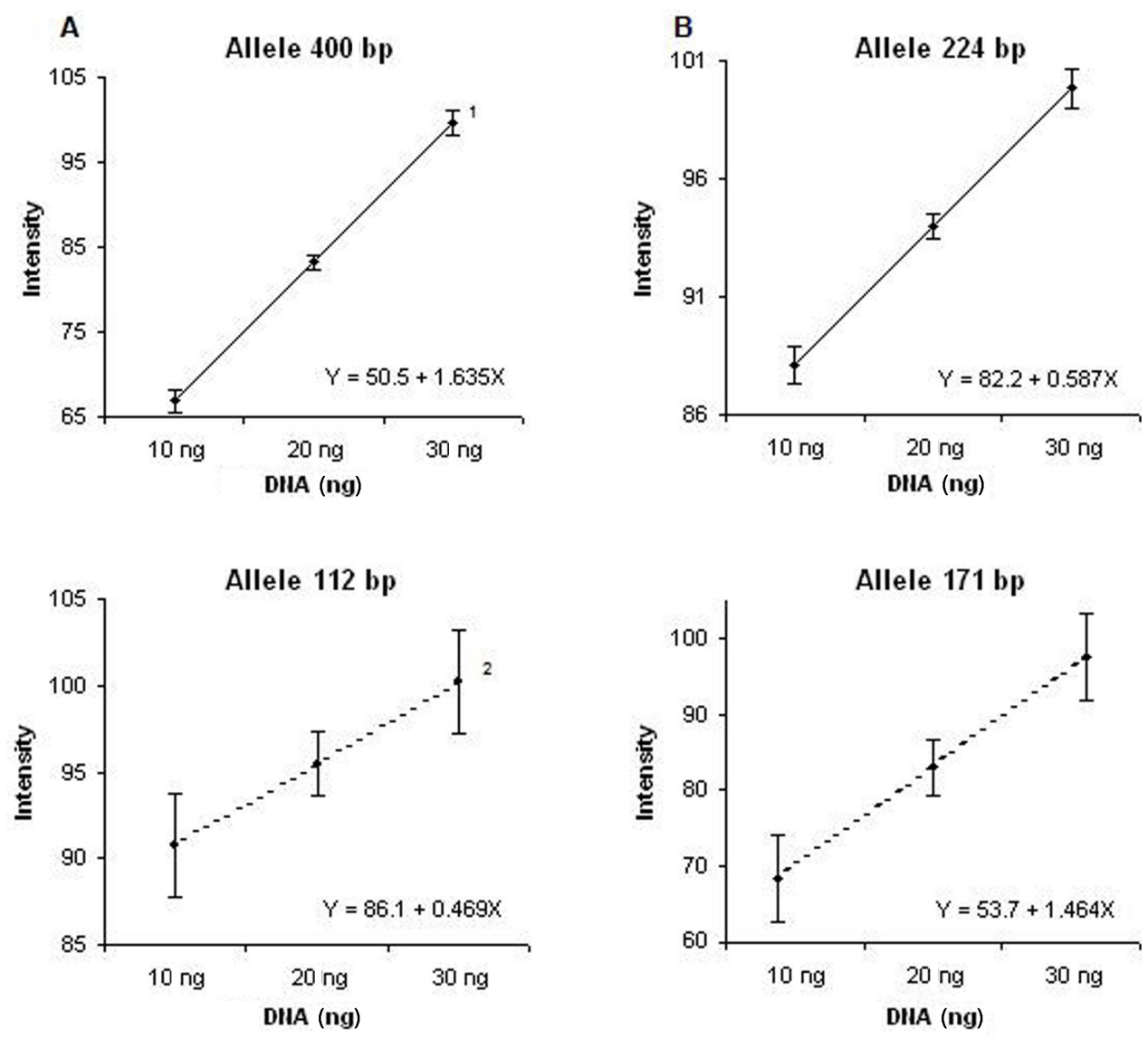

Figure 4. Standard curve for the intensity of fragments amplified with the primers bnlg182 (A) and $b n \lg 1006$ (B) plotted versus the initial DNA amount in the samples, in ng. 1 and 2 refer to the alleles of smaller and larger size, respectively, in bp. The confidence interval, at $5 \%$ probability, is indicated by symmetric bars.

When the analyses with both primers, simultaneously, was considered, only in one of the nine samples it was not possible to determine the initial DNA amount, showing that SQPCR, followed by regression analysis, was efficient in distinguishing samples in 
relation to their initial DNA amount. Thus, it is concluded that this method can be applied for increasing accuracy in QTL mapping, by decreasing the number of non-informative individuals in outbred populations. However, it is noted that SQPCR requires previous knowledge of the reaction kinetics for the primers to be used, as well as standard samples with a known number of allele dosages.

\section{ACKNOWLEDGMENTS}

Research supported by Conselho Nacional de Desenvolvimento Científico e Tecnológico (CNPq), Fundação de Amparo à Pesquisa do Estado de Minas Gerais (FAPEMIG) and Embrapa Milho e Sorgo.

\section{REFERENCES}

Baffi MA, Vieira CU, Siquierolli AC, Bonetti AM, et al. (2004). Expressão do gene hormônio juvenil metiltransferase em abelhas Melipona scutellaris (Hymenoptera, Apidae, Meliponini). Arq. Inst. Biol. 71: 378-380.

Barabás É, Nagy K, Várkonyi V and Horváth A (2001). Comparison of the quantitative competitive and semiquantitative RT-PCR methods for the determination of interferon-gamma mRNA levels in AIDS-free HIV-infected individuals. Braz. J. Med. Biol. Res. 34: 1271-1275.

Cazzola ML and Petrucelli S (2006). Semiquantitative analysis of genetically modified maize and soybean in food. Electron. J. Biotechnol. 9: 320-325.

Chelly J, Montarras D, Pinset C, Berwald-Netter Y, et al. (1990). Quantitative estimation of minor mRNAs by cDNApolymerase chain reaction. Application to dystrophin mRNA in cultured myogenic and brain cells. Eur. J. Biochem. 187: 691-698.

Coelho ASG (2000). Considerações Gerais sobre a Análise de QTL's. In: Análise de QTL no Melhoramento de Plantas (Pinheiro JB and Carneiro IF, eds.). FUNAP, Goiânia, 1-36.

Cruz CD (2006). Programa GENES - Estatística Experimental e Matrizes. Universidade Federal de Viçosa, Viçosa.

Da Y and Lewin HA (1995). Linkage information content and efficiency of full-sib and half-sib designs for gene mapping. Theor. Appl. Genet. 90: 699-706.

Dutta A, Singh D, Kumar S and Sen J (2007). Transcript profiling of terpenoid indole alkaloid pathway genes and regulators reveals strong expression of repressors in Catharanthus roseus cell cultures. Plant Cell Rep. 26: 907-915.

Ferre F (1992). Quantitative or semi-quantitative PCR: reality versus myth. PCR Methods Appl. 2: 1-9.

Gause WC and Adamovicz J (1994). The use of the PCR to quantitate gene expression. PCR Methods Appl. 3: S123-S135.

Liu BH (1998). Statistical Genomics. CRC Press, New York.

Marin LJ, Cunha AA, Aquino VH and Figueiredo LT (2004). The use of qualitative and quantitative polymerase chain reactions for diagnosis of cytomegalovirus infections in bone marrow and kidney transplant recipients. Rev. Soc. Bras. Med. Trop. 37: 158-164.

Saghai-Maroof MA, Soliman KM, Jorgensen RA and Allard RW (1984). Ribosomal DNA spacer-length polymorphisms in barley: Mendelian inheritance, chromosomal location, and population dynamics. Proc. Natl. Acad. Sci. U. S. A. 81: 8014-8018.

Slate J (2005). Quantitative trait locus mapping in natural populations: progress, caveats and future directions. Mol. Ecol. 14: 363-379.

Tanksley SD (1993). Mapping polygenes. Annu. Rev. Genet. 27: 205-233.

Tao N, Hu Z, Liu Q, Xu J, et al. (2007). Expression of phytoene synthase gene (Psy) is enhanced during fruit ripening of Cara Cara navel orange (Citrus sinensis Osbeck). Plant Cell Rep. 26: 837-843.

Tozzini AC, Martínez MC, Lucca MF, Rovere CV, et al. (2000). Semi-quantitative detection of genetically modified grains based on CaMV 35S promoter amplification. Electron. J. Biotechnol. 3: 149-153.

Underwood MA, Bartlett JM and Cooke TG (1994). An improved method for semiquantification of gene amplification from archival material. PCR Methods Appl. 4: 178-184.

Wu R, Ma CX, Gallo-Meagher M, Littell RC, et al. (2002). Statistical methods for dissecting triploid endosperm traits using molecular markers. An autogamous model. Genetics 162: 875-892. 